\title{
Towards a Research Agenda for Informal Logic and Critical Thinking
}

\author{
MARK WEINSTEIN Montclair State College
}

This paper recommends that the recent concern with informal logic and critical thinking be redirected from its general philosophical focus and towards a greater appreciation of the particulars of practice in the various domains of human understanding. The redirection recommended is prompted by the central role that critical thinking and informal logic can be seen to play in meaningful educational reform, especially at the undergraduate level. Such a central role is implicit in many of the texts and theoretic discussions within the expanding field, and has been made explicit in the writings of some of the most thoughtful advocates of critical thinking. In order to render the recommendation plausible, the paper will sketch an image of informal logic and critical thinking that places the field within three significant contexts. These contexts include the circumstances within which the field was first developed, some theoretic assumptions common in the field's understanding of itself, and finally, the educational framework within which the field's endeavors take place. Relative to informal logic, the recommendation is that argument analysis should evolve into what has been called "applied epistemology." 1 Critical thinking, similarly, should be redirected from concerns typical of philosophers and towards issues and approaches more representative of critical thinking both within and across the wide range of disciplines represented by the course of undergraduate studies.

A number of quite particular consequences will result from the position developed in the paper. Among them is the view that the seminal work of Stephen
Toulmin has been too hastily criticized and seen as lacking, and that Toulmin's analysis of the structure and function of argument should be placed at the center of work in informal logic. Next, that the current concern with ordinary argument needs to be moderated by a deepening appreciation of what I call "stylized" argument, that is, argument within the various special disciplines. ${ }^{2}$ Last, that informal logicians and critical thinkers, working within undergraduate education as proponents of educational reform, must develop collaborative approaches that draw the members of all of the academic disciplines into an ongoing dialogue in which all participants are equally valued contributors.

\section{Informal logic and applied epistemology}

Recent concern with informal logic begins against the backdrop of the teaching of aspects of symbolic and traditional logic as a standard undergraduate course in philosophy. First level logic courses, with their typical mixture of fallacies, fragments of formal logic, linguistic analysis and rudimentary scientific method were presented in order to accomplish at least two educational objectives. The first of these was to offer an analysis of argument and the beginning of a method of argument assessment and the second to furnish some foundational knowledge and help develop basic reasoning skills. The latter objective was based on a vague, but traditional notion, that the teaching of logic is relevant to the teaching of thinking. The former was 
based on the equally venerable notion that argument analysis is relevant to argument assessment and that skill in argument assessment enables students to, in some sense, develop the skills and even dispositions of reasonable persons, traits and abilities now commonly identified with critical thinking. ${ }^{3}$

It was the inability of the then standard introductory logic courses to achieve these ends, and the compelling nature of the ends themselves, that furnished the impetus for informal logic. ${ }^{4}$ Thus, informal logic stands between formal logic on the one hand and critical thinking on the other. And as such, informal logic is subject to two opposing tensions. The first of these prompts concern with analogues to formal principals, context independent criteria for identifying and assessing arguments. The second demands that informal logicians offer an educational program that is of general utility, enabling students to better assess arguments both in their courses of study and in their everyday lives.

The logical aspect of the informal logic project has been taken to include a theory of argument structure (functionally analogous to syntax in formal systems) through the circle arrow diagrams, now commonly accepted as the most adequate means of representing arguments, and apparatus that addresses the acceptability and unacceptability of inferential relations (analogous to semantics). The latter has been, for the most part, limited to fallacies, both traditional and newly defined.

The model of formal logic and the deeply rooted tendency of philosophically trained informal logicians to search for purely general and, hopefully, a priori principles (or at least principles that require no more than an analysis of language and common sense) has resulted in a predisposition that, as I shall hope to convincingly argue, creates problems for the satisfactory application of informal logic as a tool for critical thinking.

Critical thinking is, whatever else, an educational ideal of great breadth and pro- fundity. It has been identified with reasonableness in general, as in Harvey Siegel's definition of the critical thinker as one who is "appropriately moved by reasons." " And it has been identified with the most all-embracing notion of the intellectual virtues, as in Robert Ennis' characterization of critical thinking as "reasonable and reflective thinking focused on deciding what to believe or do" 6

It is such very general objectives that, so it seems to me, require that informal logic move beyond the logical in order to embrace what might be called applied epistemology: that is, the study of the epistemologies in use in the various domains of human understanding in order to ground the assessment of arguments as they occur within them. Notice, that I am assuming that there are distinguishable domains of human understanding, that the domains of human understanding have epistemologies, and that these need to be made explicit, if informal logic is to lead to critical thinking. ${ }^{7}$ Needless to say, my claim is controversial, since, for among other reasons, it implies that pure epistemology is insufficient to the task of critical thinking. That is, I maintain that epistemology that is purely philosophical and independent of the various domains of inquiry cannot effectively result in critical thinking in the broad sense required by the educational ideal sustained in its name. ${ }^{8}$ Notice also that this implies that the domains of human understanding are generally relevant for "deciding what to believe or do." My position is that domain specific knowledge, including knowledge of the epistemologies of domains, is relevant for critical thinking both within and across domains, and in relation to ordinary affairs: those "real life problems" that have been the focus of much of the theory and practice of informal logic. ${ }^{9}$

The need for an applied epistemology is grounded in the nature of informal logic itself. For if the assessment of arguments is to be seen through the analogy with formal logic, what is required is both a theory 
of premise acceptability (analogous to say, a Tarskian definition of truth) and some account of how acceptability is transmitted from premises to conclusions (analogous to semantic entailment). ${ }^{10}$ The theory of fallacies, in such an image, shows how various fallacious moves block acceptability from being transmitted through the chain of argument from premises to conclusions. But notice an important asymmetry between a theory of fallacies and a theory of semantic entailment. Fallacies shows how the chain of argument is broken, not how the chain is validated. The asymmetry is sufficient to account for the attractiveness of deductivism in informal logic, since if all appropriate arguments are deductive than no semantics other than that of the preservation of truthlike properties is required.

Unfortunately for generalist tendencies in informal logic, the deductivist solution has been generally seen to be unattractive, at least if we mean the sort of deductivism that makes all arguments analytic or nomic entailments. Trudy Govier's careful arguments found most recently in Problems in Argument Analysis and Evaluation, " seem compelling when she points out, both by abstract reasoning and persuasive examples, the inappropriateness of the very general universalizations that would be required if deductivism is to be sustained in the contexts of argumentation that informal logic is most concerned with. There is, however, another sense of deductivism that needs to be distinguished from the one just mentioned. That is the notion of deductivism that is parasitic on the minimal conditional. As has been noticed by almost everyone who has discussed the issue, to present premises $p_{1}$ through $p_{\mathrm{n}}$ and conclusion $q$ is to assert at least the material conditional if $p_{1}$ and $\ldots$ and $p_{\mathrm{n}}$ then $q$. Thus, elementary deductive relations of the sort captured by modes ponens and modes tollens are built into the very fabric of argumentation. In this sense deductive moves are always included in argumentation and the correlative deductive fallacies are always appropriate means of critique. But again, as Govier has argued, the minimal conditional in no way extends the force of the argument beyond the stated premises and thus, in no way guarantees the stronger sense of analytic or nomic entailment that is required if the premises are to, non-trivially, imply the conclusion. By 'non-trivially' I mean imply them without the addition of the minimal conditional generated ad hoc.

The unavailability of deductivism has serious consequences for informal logic as a tool for argument assessment. For, as just mentioned, the fallacies merely show why arguments fail, and so, what is needed is additional apparatus to demonstrate how arguments succeed. This opens the door for what I have called applied epistemology. For I will claim that the assessment of the strength of support premises afford conclusions can only be assessed when the domain within which the argument is presented is taken into account. To use a distinction I owe to Rob Grootendorst, ${ }^{12}$ fallacies are norms for argumentation that cannot be violated, if it is to be reasonable, but they do not afford criteria that allow us to assess the degree of success with which a set of premises support a particular conclusion. That is, assessing the success with which premises support conclusions requires, in the words of Tjark Kruiger, another member of the Amsterdam school, appeal to "mutually accepted testing procedures," and a "mutually accepted system of logic, " 13 in my terms, accepted principles of methodology and substantive generalizations and analytic hypotheses. ${ }^{14}$

\section{Toulmin and stylized argument}

The rejection of a thoroughgoing deductivism has consequences for the assessment of arguments, for if the relation between premises and conclusion is not deductive, then some sense must be made of the claim that particular premises offer varying support for the conclusion. This can 
not be accomplished through argument diagramming alone, especially if diagrams are limited to identifying premises and conclusions. But even where diagrams are complicated by a more sophisticated notion of the roles of premises in argumentation, difficulties with levels of support still persist. ${ }^{15}$

This can be most easily seen if we accept Toulmin's model as a plausible account of the complex roles of premises in arguments. ${ }^{16}$ For as Toulmin maintains, the structure of functional roles he identifies is dependent on particular methodological principles in the domains within which argumentation occurs. The notion of warrant serves as a telling example. Toulmin sees warrants as sentences that show the relevance of grounds to claims. In science, for example, a warrant might be a covering law showing a functional relationship between data and some predicted outcome. ${ }^{17}$ But as many of Toulmin's early critics maintained, data can be challenged in other ways. In particular the data may be relevant in the sense that they are appropriate to some generalization, but yet may be methodologically suspect. ${ }^{18}$ The data may be challenged, not only in respect of their relevance, but also as regards their facticity. But, how are such challenges to be distinguished, how are warrants presented in response to such concerns to be identified? The answer seems obvious to me, such differing warrants can only be identified if substantive knowledge of the domain within which the argument takes place is brought to bear on the issue. Further, how can such warrants be assessed? How do the different considerations render the conclusion more or less worthy of belief? It seems to me that only a sense of the basic epistemological issues in the field could possibly help. How well entrenched are the generalizations, how canonical is the methodology, what latitude is acceptable in practice? Clearly these are domain specific issues, and not merely issues of fact, but rather, issues that refer to substantive methodological assumptions that govern inquiry in the domain.

It might be countered that even if Toulmin's model of argument is correct as an analysis of arguments in the stylized context of the special disciplines, it is irrelevant to the practice of informal logic in respect of its most essential domain of application, that is ordinary argumentation. I now turn to that concept.

The distinction that the concept of ordinary argumentation was seen to make, contrasted ordinary arguments with the argument samples that were frequently presented in logic textbooks. Turning sample arguments into overt and formally expressed implications requires that the argument samples offered be treated as constituted, at least in their essential aspects, by those formal renderings that become the textbook's exercises in derivation and proof. Translation, the rendering of ordinary arguments as formal proofs has been, thus, a significant component of introductory logic texts. The artificiality of this process prompts two separate quasi-deductivist moves, first, the concern with missing premises as a necessary addition to ordinary arguments if arguments are to be rendered as valid: ${ }^{19}$ second, the attempt at alternative reconstructions based on core notions of validity so that arguments can be assessed holistically without regard to the strength of individual premises. A characteristic example of this sort is the possible world interpretation that utilizes the notion of a counterexample to validity claims as an essential core, while relinquishing the details of logical reconstruction. ${ }^{20}$

As evidenced by the recent literature, both of these strategies create as many problems as they resolve. ${ }^{21}$ But there is a more fundmental problem with these typical quasi-deductivist accounts. Contrasting ordinary arguments with those in formal languages obscures a more relevant distinction. That is, the distinction between ordinary argumentation as contrasted with the more stylized argumentation common in 
specific subject domains. Argumentation seen in relation to an enhousing domain and discourse community exhibits differing and characteristic styles of argument, specific "inference tickets" (warrants), particular epistemologies (backing), and individual requirements for closure. ${ }^{22}$ This for me is the insight Toulmin's position affords.

Seeing argumentation as occuring within paricular domains, does not, however, mean that a given argument need be limited to some particular domain. Many of Toulmin's critics appear to confuse the former view with the latter, and therefore see the unavailability of a uniquely identifiable domain for particular argument fragments as a problem for Toulmin. It is not. But, more importantly, such criticism has resulted in a pernicious non-sequitor that seems implicit in the views of many informal logicians and critical thinking theorists. That is, if no particular enhousing domain is identifiable, the argument needs to be assesssed by the growing sub-discipline of philosophy, informal logic and critical thinking. ${ }^{23}$ This, if my view is right, is a disaster for any argument that requires domain specific considerations for its appropriate analysis and assessment. Arguments can, in general, be presented and developed in different ways in many fields. Short argument samples may have been abstracted from discussions in a field (if they are real and substantial), but in the textbook they stand alone. If they are examples representative of a vast number of sample argument used in texts, they are available to many fields. Arguments can be framed by many different kinds of considerations. Doubtful claims can be addressed from many disciplinary points of view and many combinations of disciplinary perspectives. The question is, which fields and which approach yields what kinds of success in analyzing and developing the salient aspects of the argument, finally, offering an adequate assessment of the various considerations put forward as arguments in respect of the points at issue.

\section{Critical thinking across the disciplines}

The sense that there is an internal relationship between arguments, argumentation and domains of knowledge persists despite attempts to show relevant and useful notions of critical thinking that are generally available for instruction and neutral in respect of the disciplines. The resolution of the issues generated by these competing views, requires that reflective practitioners of the disciplines, students of the history of ideas, methodologists and specialists in teaching increasingly engage in the task of generating and organizing the data upon which an informed and adequate notion of critical thinking across the disciplines must be based.

My own research responds to such an agenda. Increasingly, my interest involves working with colleagues from a variety of disciplines attempting to analyze and contrast methods in the various fields, what has been called by John McPeck and others, the "epistemology of the disciplines." 24 If the locus of critical thinking is to be found in the particulars of disciplinary language and modes of inquiry, then critical thinking, at the undergraduate level at least, will require a focus different from the common concern with topic neutral skills and dispositions. At Montclair State College some of us are attempting to grapple with the reformulation of the focus of critical thinking through the study of the disciplines in an "ecological perspective." 25 This requires a systematic exploration of the continuities and differences in language and inquiry across the various fields; the relation of particular disciplines to multi-field concerns; and the application of disciplinary knowledge to broad, "real world," problems.

The ecology of the disciplines develops a stance in relation to real-world multilogical issues. We accept the fact that methods within the disciplines are frequently inadequate to problems that transcend narrow disciplinary frames. But we insist that information drawn from within these 
frames is necessary, if the multi-logical problems are to be addressed in an informed and responsible fashion. Further, we maintain that information from the fields includes substantive methodological principles, principles of epistemological and logical relevance that are drawn from the practice of the disciplines and that are not available in the general characterizations of methodology developed by philosophers working in abstraction from practice. The ecology of the disciplines also includes a perspective that sees methodological insight to be garnered from the comparision of methodological principles in the various disciplines, This requires the detailed description and assessment of disciplinary practice from the points of view of diverse disciplines. Such a cross-disciplinary perspective certainly includes methodology drawn from the work of philosophers, but philosophy is not uniquely relevant to this study, Philosophers work in specific ways, perhaps in ways that are useful as contrasting points of methodological perspective, but so do sociologists, art historians and chemists. ${ }^{26}$ There is no a priori argument that I accept that substantiates the claims of any discipline to methodological priority.

The lack of arguments that demonstrate a priori precedence of any argument style or disciplinary approach should not be confused with the argument that shows the a priori necessity of some argument or other required for even the most abstract rational disputes. For the latter, as demonstrated by Plato in the Theatetus and reiterated by Harvey Siegel, shows the availability of a non-question begging argument to be a necessary condition for rational justification within disputes in general. ${ }^{27}$ Siegel employs his version of Plato's argument in a variety of ways and against a variety of targets, but he shows particular concern with a view that is a cousin of the one argued here: the emphasis on disciplinary particulars as essential for epistemological concerns. But we still must distinguish the two points, for a concern with disciplinary norms, does not preclude interdisciplinary assessment. Siegel is clearly correct in maintaining that inter-disciplinary assessments must be based on good reasons, but it is equally clear that there is no reason to suppose that such standards for assessment must be drawn from philosophical epistemology whether as currently understood or as understood by some future heir of the contemporary philosophical tradition. ${ }^{28}$ For, contrary to Siegel, I maintain that it remains to be seen whose methodological practice is best suited to constitute the forum within which particular cross-disciplinary assesssments are to be made. Historically, philosophers, being concerned with the most abstract principles of inquiry have played the role-frequently self-appointed-of court of last resort in methodological disputes. Certainly, the practice of assessing methodology at the highest level of abstraction can be called philosophy with historical and philological warrant. But that is not the issue. The issue for me is, rather, to identify the domains from which the most adequate methodological concept set is to be drawn. Call the result philosophy if you will, the issue is still from whose practice is epistemological warrant to be drawn, and in which cases. Is the a priori practice of philosophers to be the model, or is it rather the hermeneutic analysis of literary theorists; is it the narrative explanations of historians, or the descriptive and analytic offerings of sociologists, the axiomatic practice of mathematicians, the theory bound derivations of physics, or is it, perhaps, the inductively generated accounts common in the social sciences? Which of these, and in which combination, in respect of what aspects, and on which particular occassions?

The preceding remarks offer an argu ment scheme applicable to the vast majority of critical thinking skills identified in lists of critical thinking concepts. So, for example, whose notion of causality is most relevant to critical thinking, the historians', the literary critics', the quantum physicists' or 
the educational psychologists'? Or is it rather some philosophers' and if so which of those available in a rich and varied literature? Analyses of causation, judging from classic and contemporary philosophical texts, include a host of related but distinguishable notions. Looking at practices in the various disciplines increases the available models for understanding causality. To ask, as do some critical thinking theorists, that students be helped to adjudicate which of various causal claims is most adequate, is to require that students be familiar with the various ways that causal claims are grounded in the various domains of inquiry. There is just no univocal analysis of causation that stands as the final court of appeal..$^{29}$ The same is true of other central epistemological concepts. Whose notion of observation is most salient to a given multi-logical dispute, the art critics', the neuro-physiologists', the cognitive scientists' or the chemists'? What standards for authority are required, the sociologists', the political scientist's or the theologian's? Whose requirements of clarity should be sustained, the poet's, the bio-chemist's or the geometer's? Such issues, I maintain, can only be joined by contrasting available concept sets and looking to our epistemological purposes. The various domains of knowledge all have particular insights to offer. These domains include philosophy as a member. Philosophy does not, however, exhaust the available methodological insights, neither through its method nor through its concepts.

The focus I have been describing, an ecological perspective on the disciplines, shifts both the normative and descriptive core of critical thinking. The concern is less with the general concepts of informal logic and more with the concept maps that govern assessment of information in the fields. Most importantly, an ecological approach leaves open the possibility that abstract epistemological arguments drawn from the work of philosophers are not the court of last resort, that successful practice in the various disciplines has normative force, and that critical thinking must be closely tied to sound educational policies consistent with an adequate knowledge base in the various domains.

\section{Critical thinking and the language of the disciplines}

The preceding is, perhaps, most persuasive to those who already share my convictions. What is missing is a deeper theoretic analysis that exhibits the general structure of argument in a fashion that exposes its disciplinary underpinnings. I believe that such a theory is available, and in fact, grows out of an analysis of argument that sees an intimate relationship between argument and language. Language, in such a theoretic analysis must, however, be seen in its full complexity, especially when the focus is on language as it is employed within the context of inquiry in the various disciplines. What I will now turn to is the beginning of a sketch of language in use that will point to the deep connection between language, argument and inquiry. But first a word about critical thinking.

As is by now, perhaps, well known, The Institute for Critical Thinking takes critical thinking to include the skillful, selfcorrective and context-sensitive use of criteria. Critical inquiry thus requires the identification and reasonable application of criteria appropriate to the context of inquiry. ${ }^{30}$ But where are these criteria to be found and how is the notion of critical inquiry related to the language in which it is embedded? It should not be surprising, given the perspective outlined above, that the answer to these questions should be found in the particular role that the disciplines play as a crucial context for inquiry. To see this, it is necessary to explore the relation between the disciplines as the locus of inquiry, and the languages within which inquiry takes place.

Language as related to the disciplines 
can be differentiated into three essential aspects. The first two are general; the last addresses the disciplines in their relation to undergraduate education. These three aspects of language are:

1. Language as a "language game," to use Wittgenstein's pregnant phrase. Expressive of a "form of life," language includes a set of paradigmatic practices that underlie the particular concepts and argument types characteristic of a discipline. ${ }^{31}$ Language as "language game" relates the overt language in use to the lived reality of practitioners of the discipline, and draws from the historical experience that gives each discipline its characteristic profile.

2. Language as a specific set of concepts and argument prototypes: particular vocabulary and characteristic modes of organizing disciplinary content, that reflect practice, permit disciplinary communication, and set the stage for the development of appropriate tasks that initiate new members into the field.

3. Language as a set of basic competencies required of students and assessed through tasks deemed necessary, if students are to demonstrate understanding of the discipline and the information and procedures that it includes.

Such a schematic representation remains opaque without a few telling examples. Perhaps the following will offer some sense of how the specifics of various disciplines point to the need for a careful look at the particulars of disciplinary inquiry as related to the three aspects of language presented.

\subsection{Language as the expression of a "form of life"}

To take an example: In Philosophy a central paradigm shows a marked discontinuity with an analogue in Chemistry. Philosophers take the practice epitomized by Socrates as a basic model for inquiry. That is, the practice of doing Philosophy includes at its core, careful and pointed questioning whose purpose is to elicit and clarify concepts that are thought to be already available to the philosophical thinker, either as intuitive knowledge or perhaps as the result of the internalization of conceptual frameworks and linguistic structures. It is evident from such practice that philosophers maintain that basic philosophical concepts are available to reflection and can be clarified through dialectic.

In Chemistry, on the other hand, the central paradigm is based on the procedures of classic chemists such as Lavoisier and Dalton. These procedures are quite specific: weighing, heating and combining in simple proportions, and are a small sub-set of the possible procedures that could be applied to material substances. The success of these initial methods of inquiry leads chemists to look to analogous procedures. This reflects the field's fundamental assumption that complex chemical phenomena are best explained when shown to be the result of analogues of these primordial practices (analysis in terms of mass, measurement of electrical resistance and the like).

\subsection{Language as concepts and arguments.}

Language in this sense offers an even clearer image of the differences that characterize inquiry in the disciplines. Each discipline includes both a set of concepts and a logic-a set of tacit or explicit rules governing how discourse is to be organized for presentation, challenge and defense. In Classical Economics, for example, typical concepts include value, exchange and market. Their variants pervade Economics as a discipline and importantly define a prototypical argument type: the explanation of economic behavior in terms of subjective preferences and descriptions of market force deemed relatively objective and describable in quantitative terms.

A far removed example of similar structure is the analysis of harmony in Music in terms of Dominant and Tonic. Both musical analysis and composition reflect this in prototypical dominant-tonic relations, these 
include harmonic substitutions $(G \mathbb{H} \min 7$, $C \# 7$ in $C$ major) and large formal analogues (Sonata-Allegro principle).

\subsection{Language as a set of student competencies.}

This involves the set of student skills required in the disciplines, and helps to specify student tasks and grounds the assessment of student achievement. Analogous to reading and writing, such skills are grouped around information gathering and information use. These vary in obvious ways: understanding and producing laboratory reports in Physics, and reading and writing short stories in English. There are more subtle distinctions as well. Take as an example, the contrast between analyzing a classic philosophical text to draw out its main points and writing an analytic essay showing where crucial philosophical difficulites lie, on the one hand, as compared to reading original documents to develop a sense of an historical period, and using documents to argue for a particular perspective or interpretation of an era, on the other.

\section{Critical thinking as an educational goal}

Given the apparent discipline specificity of the languages presented above, the obvious question is: Is critical thinking, and its supporting discipline, informal logic, as currently conceived, sufficient to engender critical thinkers in particular fields and at various educational levels? Before we continue, however, it should be immediately conceded that much of what is included in the current conception of critical thinking is general, discipline neutral and relevant to aspects of instruction in a variety of college courses, as well as to arguments that can be characterized as involving issues of daily life. But are those aspects, conceived as general and subject neutral, adequate to educational objectives consistent with the goal of critical thinking and appropriate to undergraduate education? ${ }^{32}$

A procedure for testing the current notion is available from Harvey Siegel's account of the ideals underlying critical thinking found in Educating Reason. And so the question is: How far does the current conception go towards addressing "respect for students as persons...self-sufficiency and preparation for adulthood...initiation into the rational traditions...(and)...democratic living"'? ${ }^{33}$ The answer seems to be: Not very far at all. Although critical thinking instruction may furnish students with a budget of concerns, it is not clear that these concerns are readily translated into the complex contexts of their other courses or their ordinary affairs. Nor is it clear that such concerns are equally relevant to substantive disputes, especially given the level of abstraction (or caricature) with which such concerns are represented in most texts in the field. ${ }^{34}$

Siegel, accepting the need for attention to the specifics of disciplinary knowledge, what he calls "pluralism," follows McPeck by recommending that critical thinking pay attention to the "epistemology of the disciplines." That is, critical thinking should include in its purview the standards that govern "good reasons" in disciplinary efforts to substantiate claims in their field..$^{35}$ This conception of knowledge in the fields does not sit comfortably with a position such as Paul's that sees disciplinary thinking as artificial and too narrow to address multilogical and ethical issues. Nevertheless, even if we agree with Paul that social and political concerns transcend narrow disciplinary focus, it seems plausible that information from the fields may be relevant to the amalgam of information necessary to address cross-disciplinary concerns and real world problems. How can a student be helped to evaluate and apply information from a variety of fields when responding in an informed fashion to multi-logical issues? How can students be helped to critically assess information within the range of subjects that they are required to 
master, and how can they be helped to apply such knowledge to the rich multidimensional issues that characterize social and political argument and decisions in everyday life? ${ }^{36}$

This raises a number of specific questions that define a research agenda for critical thinking conceived as relevant across the disciplines and at the undergraduate level. Do the procedures neutrally characterized by critical thinking theorists retain sufficient continuity when translated into the languages in use in the various fields? Do they retain significant similarity when instantiated in the various procedures that govern inquiry in the domains of knowledge? Are critical thinking skills, undifferentiated by disciplinary specifics, adequate to the analysis of real world problems at a level of sophistication that is appropriate to educated members of a concerned citizenry? These are not trivial ques tions. They have been a concern of critical thinking theorists for almost a decade. But they have been addressed, for the most part, on a level of generality and through philosophical arguments that seem to me inadequate for their clarification and resolution. I maintain that an adequate response to the issues such questions reflect, requires careful analysis of the particulars of the various disciplines. The brief account of the diversity of the languages of the discipline, offered above, points to a framework of argument that is relevant to the dispute. For if the various disciplines are embedded in relevantly dissimilar practices, and if these practices support and require argument structures and epistemological norms that are substantive, in the sense that good reasons are warranted through them, then the claim to significant generality and subject neutrality is weakened.

The consequences of such a research agenda are crucial to the relevance of critical thinking across the disciplines. For if my argument is sound, critical thinking across the disciplines will only become a reality when the normative function, heretofore reserved for philosophers, shifts to include the realities of concepts and practices that warrant the central role the disciplines play in furnishing much of what is worth knowing about the world around us.

One more point before we move on. Our earlier consideration of the sufficiency of critical thinking as currently conceived, points to the analagous notion of necessity. And so we might well ask: Is there some core to the notion of critical thinking that is a necessary aspect of education in the various fields, given the ends for which critical thinking is envisioned? Here too, the question requires careful analysis of actual practice. For even if there is some definable core, necessary for thoughtful practitioners in the various fields, does this core require a common set of educational strategies to be included in schooling in the various domains? Or are the particulars of disciplinary study sufficient to engender critical thinking skills and dispositions without a systematic focus on the skills and dispositions themselves?

These crucial questions require a response from critical thinking theorists concerned with undergraduate education across the disciplines. As mentioned earlier it is my conviction that working towards an appropriate response requires a research agenda that is more concerned with actual disciplinary practice and less with abstract epistemological or logical arguments. In this I see continuity with the tendency that motivated the movement from formal logic to informal logic and the shift from abstract, frequently formal philosophy of science, to the analysis of case studies drawn from the history of science. These tendencies raise profound questions as to the locus of epistemic wisdom. It is my sense that, increasingly, insights into epistemological adequacy must be drawn from successful practice and be couched in terms that reflect the complexity and sophistication of stylized argument. That is my intuition; its defense ultimately relies on the research agenda recommended here. But the intuition is 
afforded prima facie support by the analysis of language offered above. It is reinforced by my sense that critical thinking skills, characterized as general and topic neutral, gives the form of the concerns, but none of the necessary substance. And it is rendered more persuasive by examples of disciplinary particulars of the sort offered above. But that is to repeat my convictions. Additional support must wait upon the careful analysis of critical thinking skills as instantiated in the various domains. This, of course, is the reason for my call for the research agenda outlined here. But even at the level of these programmatic remarks, there is more to the issue of the adequacy of critical thinking as currently understood, to the notion of critical thinking across the disciplines and at the college level.

\section{Critical thinking in its institutional setting}

The impact of the critical thinking movement as a practical vehicle for educational reform raises additional considerations relevant to the reform of actual educational institutions. ${ }^{37}$ I claim that if critical thinking is to be effective as a vehicle for reform the issues raised must be seen within three essential contexts:

1. The theoretic context of the various disciplines.

2 . The pedagogical practices appropriate to education in the fields.

3. The pragmatic context generated by overarching institutional concerns.

\subsection{The theoretic context.}

Even if it is ultimately seen that critical thinking is generally available and neutral in respect of the methodological standards in particular disciplines, it is not apparently so, once the relevance and diversity of disciplinary languages is acknowledged. Critical thinking and the epistemological and logical criteria that are espoused in its name are not obviously identical with or readily translated into correlative principles in the various fields. Neither are the philosophical analyses afforded within critical thinking and informal logic unproblematic in themselves or in application to cases. A sobering example for critical thinking advocates is all too available from the fifty years of rational reconstructionist attempts in philosophy of science alluded to above. The attempts at logically based general analyses of scientific practice were seen as both logically suspect and descriptively inadequate by philosophers themselves. Both within and among the disciplines, faithfulness to scientific practice points up the inadequacy of the available general accounts of scientific method, of causation, of induction and of the nature and role of observation and its relation to theory.

But there is more to the problem, for the judgment of philosophers is not the only institutionally relevant judgment, if critical thinking is to reach across the disciplines. Scholars, researchers and teachers in all of the fields to be touched by critical thinking must, themselves, see the relevance of any given account of critical thinking to their efforts.

\subsection{The pedagogic context.}

Given the concern with educational reform, an acount of critical thinking offered as relevant to disciplinary issues must be appropriate and effective in teaching across the curriculum. Critical thinking theorists have questioned pedagogical practices that are common throughout undergraduate education. The use of lecture, didactic teaching, objective examinations and grading are all brought into question by critical thinking advocates who see dialogical and multi-logical pedagogy at the core of critical thinking instruction. ${ }^{38}$ This becomes an issue for any discipline whose practice supports didactic models as most appropriate for instruction in the field. The epistemological basis of critical thinking has barely been explored; its relation to theories of learning is nowhere near resolved. Standard pedagogical practices, on the other 
hand, are supported by tradition and practice and have been addressed in a systematic way by educational psychologists and specialists in teaching. Although the critical thinking movement is not without plausible pedagogical recommendations and a growing body of successful educational practice, paradigms for critical thinking instruction have been drawn from philosophy and some few other academic subject areas. It is just not obvious to me that Socratic discussion, so at home in the philosophy class, is equally pertinent to teaching calculus, or that group problem solving strategies so useful in mathematics instruction are relevant to literature, or that writing process approaches are helpful in teaching economics or sociology. Clearly what is needed is further exploration, openmindedness and careful analysis. That is to say, wherever else critical thinking is required, critical thinking about critical thinking is a necessity.

\subsection{The institutional context per se.}

Although frequently disregarded as "political," institutional issues must be dealt with if critical thinking is to play a meaningful role in educational reform. The education of undergraduates takes place in a holistic context. The various elements included in the curriculum are required to amplify each other, enabling the student to achieve his or her professional goals while responding to the more idealistic aims of humanistic education and the liberal arts tradition. The relation of critical thinking to the complex of interlocking course requirements and professional accreditation must be taken into account if critical thinking reform is to be effective in undergraduate education seen as a whole. Critical thinking across the disciplines requires a careful effort to educate faculty in the particulars of the field and to the desirability of critical thinking outcomes. This, more likely than not, requires a complex and long-term program in faculty development. Issues of the autonomy of the disciplines, of research vs. teaching, and of institutional and disciplinary reward structures are confounding variables in any program of institutional reform in the name of critical thinking. Student expectations, ${ }^{39}$ patterns of assessment and the demands of particular fields of study are all serious roadblocks to meaningful institutional change. And all of these must be resolved within the complex of personalities and politics that characterize colleges.

The concerns that each of these contexts contribute cannot be overlooked if critical thinking across the disciplines is to become a reality. For those of us who see critical thinking as more than a particular course, as more than the perspective of a particular discipline, critical thinking must be seen within the total institutional context, within the realities of teaching and within the perspective of disciplinary practice, if critical thinking is to be effective at all.

The ecological focus that I have sketched here has an additional yield in the institutional contexts within which we strive. It makes critical thinking a central concern of the entire educational community and affords an invitation to practitioners of all disciplines to join with philosophers in the epistemological enterprise. Most importantly, for educational reform, it offers a framework for the totality of college studies that requires synthesis and significance, flexibility and creativity. An ecological framework for critical thinking across the disciplines offers a real possibility of educational reform, since it gives credence to the entire range of methodological alternatives, is open to the pedagogical demands of the various fields, and welcomes all members of the college community as equal participants in the task at hand. If we accept the relevance of higher education for the larger objectives for which the reasonable life is deemed best, such an approach equips our students for their lives as citizens, as decision makers and as rational persons, for it is no less than equipping our students with what seems best in the realm of reasons as warrants for their judgments and as backing for their practices. 


\section{Notes}

1 The term "applied epistemology" is gaining increased currency in discussions of informal logic and critical thinking. One plausible use, by analogy with "applied ethics," denotes applications of concepts drawn from philosophical epistemology to extra-philosophical discourse that results in knowledge claims. My use, although not inconsistent with the preceding, refers to the identification and analysis of extraphilosophical epistemological concepts in use within substantive knowledge generating practices, most essentially the sciences and other disciplines that are paradigmatic of the most reliable and sophisticated knowledge claims humans have made to this point. By "extraphilosophical" I intend concepts that are not available within the philosophical literature, per $s e$, and that reflect the experience derived from the exploration of particular subject matters in specific ways.

I would argue that my sense of "applied epistemology" has a rich philosophical history, and, in fact, lies behind some of the major philosophical epistemologists who drew heavily from, for example, the scientific practices of their time.

2 I have introduced the term "stylized argument" in Weinstein (1990) where I use it to distingush arguments in specialized fields from arguments couched in ordinary language on the one hand, and formal arguments on the other. What characterizes stylized argument is both special vocabulary and regularized procedures, including inferential apparatus specific to the field and particular patterns of argument. An example of specific inferential apparatus would be chemical formula as used in support of explanations of chemical reactions. Patterns of argument include, for example, limits on the sorts of evidence appealed to, as in behaviorist psychology, and even such broad patterns of claim and challenge as standards for publication in professional journals.

3 The idea goes back, of course, to Socrates, Plato and Aristotle. The recent movement relies heavily on the work of Robert Ennis whose initial explication of critical thinking as, "the correct assessing of statement" (Ennis, 1962) foreshadows what remains at the heart of his conception: a long list of dispositions and abilities, which in its enumeration of critical thinking abilities resembles nothing more than an index to the sort of comprehensive logic texts that has defined the field for decades (Ennis, 1987).

4 The story has been told in a number of places. A recent version is by Alex Fisher (1988).

5 Siegel (1988), p. 8. Although Siegel's definition is acceptable as it stands, it leaves open the question of how such a concept is to be articulated in practice. See Weinstein (1990d) for a discussion of this issue.

6 Ennis (1987), p. 12. Ennis' definition has been widely accepted, although little effort has been expended in confronting just how difficult changing students' beliefs may be. See Weinstein (1990a) for a review of some of the problems identified in recent work in cognitive psychology.

7 The notion that understanding can be differentiated into domains is justifiably viewed with suspicion. The discussion surrounding P.H. Hirst's attempt at a similar project: forms of knowledge (Hirst, 1965), points to the difficulty of rigorously distinguishing the components of human understanding (Phillips, 1971). If I were to hazard an account it would begin with the following: Domains can be distinguished as a weighted function of subject matter and methodology (weighted differently in different cases). The basic insight is that various aspects of the world have been best seen to respond to different strategies for explanation, prediction and comprehension. Of course, at any given period many aspects of the world are understood in competing or even incommensurable ways. Further, different aspects of the world, respond to similar methodological approaches. This makes life difficult since, for example, some areas of the academic subject area called psychology are methodologically closer to quantitative sociology than they are to other areas of psychology which are, in turn, methodologically similar to, say, various areas of literary criticism. Thus, domains do not fit neatly into the standard subdivisions of academic practice.

This creates problems for critical thinking theory construed as applied epistemology, while pointing to the enormous need for the project that my view recommends. For a rational understanding of subject matter across the curriculum requires that some articulation of methodological similarities and differences both within and across the academic disciplines be 
attempted, that is, if we agree that the ideal of critical thinking requires that students understand the information in courses within a nexus of justification and application. On such a view, courses in particular academic disciplines need to provide their students with a range of different considerations supporting their practice: frequently such considerations are methodological and metaphysical, as frequently they involve historical and social concerns, and almost always they involve consideration of the needs of practice, utility and understanding. But all disciplines owe their students an account of why their procedures are deemed best, and how their procedures appeal to the concerns of humans.

Such a schematic presentation may be less than persuasive to those epistemological uniformitarians who focus on underlying similarities. I rely heavily on examples to make my case for the central epistemological role of disciplinary specifics. This creates two sorts of problems. The first is the Plato-like demand for general descriptors. I prefer the Wittgensteinian mode: " assembling reminders for a particular purpose" (Wittgenstein, 1956, 127). A general argument is subject to a philosophical analysis in terms of necessity and sufficiency. This frequently obscures more than it illuminates, by permitting counterexamples that although compelling to the logical mind, are of little relevance to the points at issue. Recall in this regard, the cottage industry of counterexample and revision characteristic of the philosophical literature on D-N models of explanation (see Eberle, Kaplan and Montague, 1961 and Hempel, 1965). Rather than necessity or sufficiency, I prefer a salient common core of similarities and differences, an interesting "family resemblance." This raises the second objection: examples prove nothing, since apparent difference does not guarantee essential difference. Examples do not prove the case; rather, their function is to shift the burden of proof onto those who would disregard apparent differences in the name of underlying continuities. For given the salience of differences, it is up to the advocate of underlying similarities to show how the similarities are at least as illuminating as the differences for the understanding of inquiry.

Here are the sorts of examples, in question form, that press me into arguing for the discipline specificity of key epistemological concepts: How is the adequacy of a causal account assessed in literature as opposed to chemistry? What counts as an adequate obser- vation of say, DNA through an electron microscope as opposed to observations by an historian? What standards of rigor are required in laying out first principles, a geometer's or an economist's? Whose standards for deduction apply to the arguments of a mathematical physicist, to those of an evolutionary biologist? How do inductions differ in a domain that studies uniform natural kinds, e.g., geology, from induction in a domain such as social psychology? How are statistics employed in quantum mechanics as opposed to population genetics, as opposed to educational psychology? (They all satisfy the axioms of probability, but what ice does that cut?) How does narrative support analysis in literature, as opposed to case study analysis in the social sciences, as opposed to philosophical essays? And how does such analytic prose contrast with technical papers in an engineering science, or research reports in quantitative social science, or molecular biology or mathematics?

What is the point of these examples? People receive, present, analyze and assess information in widely different ways. And these ways are relevant if our students are to understand the material put before them. Critical thinking, and the assessment of arguments, for which informal logic is deemed relevant, must permit students to see what they learn as responsibly based on warrants and that the warrants are appropriately backed by the historical dialectic reflected in the methodology of the various fields. Information must also be presented so that its relevance to the domain of its application is apparent and the goodness of fit (as well as strategies for adjustment) between principles and application is identifiable for evaluation.

One caveat, I have no quarrel with a view such as Paul's when he claims that the world as well as our conceptual schemes, "can be classified in indefinitely many ways" (Paul, 1985 , p. 40 ). Rather, I would claim that there are classifications of the world and of the domains that are optimal for critical thinking conceived of as applied epistemology The thrust of this paper is that informal logicians and critical thinking advocates should begin paying more attention to what such a task requires.

8 My claim may contend with a strawman alone. Pure epistemology, in the sense of epistemology that is indifferent to discipline specific concerns, and general in respect of disciplinary practices, may be no one's cup of tea, although Siegel is clearly pointed in that direction (Siegel, 1988a, 
especially chapter 2, 1987; and also, 1980). Clarification is clearly needed. Although Siegel has offered arguments for the need for an epistemological analysis at the highest level, he offers few examples of what he has in mind. And so we might ask ourselves as a preliminary: What role do the following classic positions have to play in critical thinking across the disciplines and in relation to meaningful application in ordinary life? (substitute your own list of epistemological positions, if you will; but the thetorical thrust requires that it be an actual list with real candidates): Sense data theory? Or perhaps modern discussions of the Gettier counterexample? Humean empiricism? Cartesian rationalism? Plato's doctrine of reminiscence? Positivism? Which of these traditions is sufficient to help students to understand their education and their lives? Would combining them help? How much of them should be taught? And instead of what? How do these interface with critical thinking as standardly conceived? What is their relation to the methodological core of the other courses that students take? (For a more elaborate list of particulars see Weinstein, $1990 \mathrm{c}$ ).

9 This is argued in a number of ways throughout the remainder of the paper. See Weinstein $(1990 \mathrm{c})$ for more elaborate presentations of this last point as well as other issues raised in this paper.

10 If deductivism is not to reduce to the minimal conditional (see below in the text), some sense of the strength contributed by premises must be assessed. This requires that the relation between premises and conclusion be analyzed in other than truth functional terms. That is, that the internal connections between terms in arguments be put forward. The most reliable class of entailments, those warranted by scientific theories, the constructions of which they are comprised, and the analytical postulates that define terms and point to conceptual connections, can only be analyzed and assessed through information from within the area domains of particular disciplines. We do not, after all, get knowledge written in some ideal language composed of primitive predicates and logical connectives, and even if we did there is no uniform account of the implication relations required. Arguments in the various disciplines do not come complete with the associated Ramsey sentences and a theory of implication, and neither do arguments in ordinary language. Thus, what is required, if some modified form of deductivism is to be salvaged, is a richer and more robust notion of entailment. A beginning sketch of such a model, reflecting some of the work of this paper, is found in a paper recently read at the Second International Conference on Argumentation, June 1990 (Weinstein, 1990b) The anonymous referee reminds me of Hintikka (1989).

11 Govier (1987), chapter 5. Govier's critique of deductivism relies heavily on the unavailability of natural and plausible deductive reconstructions of actual arguments. There have been other quarrels with deductivism, for example Harman (1977), chapters 10 and 11. Most relevant, given our concern with the educational role of critical thinking and informal logic, are trends in cognitive psychology that point away from the usefulness of formal deductive or probabilistic logic for understanding actual reasoning. I have explored these issues in Weinstein (1988a), citing many of the seminal works in the bibliography. A recent work that offers a radical reconceptualization of the structure and function of logic based reasoning, offering a theoretic synthesis of recent work in cognitive science, is Margolis (1987).

The relation between philosophical norms and empirical discoveries has been the focus of much discussion; one of the most salient discus-sions is found in Cohen (1981) and the responses that it prompted. The issue to me seems to be centered around which practice should be normatively central, the heuristics employed by ordinary people, the a priori practice of philosophers, or the standards implicit in the practice of the various disciplines, science most typically. It is such issues that applied as contrasted with pure epistemology brings to the foreground. The "ecological approach" to critical thinking that is described below operationalizes this concern through the model developed at Montclair State (section 3 below; n. 25 and n. 37.) Obviously, this paper is a call for allies in this effort, which includes, among other things, some determination of the normative priorities given underlying tensions in the theory of reason.

12 The position is to be found in Grootendorst (1989).

13 Kruiger, (1989) read at TISIL. An abstract of the paper can be found in Informal Logic, vol. 11 (1989) p. 50.

14 The beginning of an analysis sufficient to support this claim is found in section 4 , below, 
where I begin an account of the language of the disciplines. The upshot is that methodology is carried by both practices and maxims, aspects of language that are internalized when learning a field "from the inside." It is my contention that students should be helped towards explicit knowledge of such methodological particulars as they learn discipline-bound knowledge.

As far as the term "substantive generalizations" is concerned, think of the role of differential equations in Physics. They tell you what the relationships between entities are, but also limit the available descriptions of data, the acceptable manipulations, and point to areas of connection with related issues both within and outside of the domain of inquiry. Knowledge that is built right into the equations limits what and how we can say and do things in the field, therefore the term "substantive generalizations."

15 Freeman (1988) offers such an elaborated model. What seems to be required in addition to Toulmin's apparatus is a supporting theory of entailment, general in respect of the particulars, but yet sensitive to the actual context of argumentation (Weinstein, 1990b).

16 Toulmin (1969) and Toulmin, et al. (1979).

17 Using Toulmin to make my point is question begging enough to give me pause. Toulmin is, admittedly, the philosopher in the informal logic movement who best represents the sorts of concern with the disciplines that I advocate. But, although that gives my position little enough support, something else does. Toulmin is also the individual who has offered the most detailed account of argument analysis to date, especially if you permit me to beg the question once again, by pointing to Toulmin's historical works that outline the course of argument using actual cases from the history of science (Toulmin and Goodfield, 1961, 1962, 1965). What I see in the disciplines, and find reflected in Toulmin's historical work, are arguments of considerable complexity, arguments that are invariably sensitive to the methodological context and the particulars of the problem situation at the time. If what is required is an account adequate to the phenomena, Toulmin is the most likely candidate in a field of one. He is not only complex but thoughtful, a student of the history of science and a philosopher of insight.

Toulmin's model of argument analysis has worked for me in workshops with teachers of writing and with reading specialists, with social scientists and historians, physical scientists and teachers of the applied arts and sciences. For one such experience, see Weinstein (1989). The newsletter, Inquiry: Critical Thinking Across the Disciplines has an ongoing record of workshops with Montelair State College faculty, the overwhelming majority of which use aspects of Toulmin's account.

The testimony is clear; Toulmin's framework speaks directly to faculty and their discipline-bound understanding. The model makes connections with how they see their disciplines, and through its use, they can appreciate what I am about as a critical thinking advocate in the context of undergraduate education. In addition, my own work in the analysis of scientific argument finds Toulmin's structure furnishing an illuminating perspective and an available tool (Weinstein, 1990e).

18 Manicus 1966), Johnson (1981), perhaps Toulmin's most detailed critic, argued against Toulmin's model based on the difficulties of distinguishing warrants and backing in the examples offered in Toulmin's introductory text (Toulmin, et al., 1979). Certainly this difficulty renders Toulmin's text difficult to use. But the problem seems to me to be general in respect of informal logic textbooks whose exercises are readily rendered ambiguous if the arguments are reconstructed within differing contexts (Weinstein, 1982). The problem seems to be less the analytic framework employed, and more a function of the artificially simplified arguments in most logic texts, presented devoid of significant context.

19 The reason for the phrase "quasi-deductive" is to mark the issues of concern as equally relevant to formalized inductive argument (probabilistic argument). Although informal logicians have generally not involved themselves in discussion of formal theories of inductive inference, the classic discussions of Bayes's theorem show structural continuity with problems of deductive reconstruction. So, for example, the discussion of Suppes (1966) points to the need for contextually sensitive reconstructions of formal inductive argumentation, even in the context of mathematically sophisticated apparatus.

20 Nolt (1984).

21 The most notorious problem involves the so called "principle of charity. "For a comprehensive discussion see Govier (1987), chapter 7. For problems with the possible worlds approach 
see, Kahane (1964); Thomas (1964).

22 Toulmin (1969); Toulmin, et al. (1979). The term "inference ticket," is Ryle's (Ryle, 1949, p. 121). The most elaborate use of the term in a sense relevant to science is in Toulmin (1953, chapter 3.)

${ }^{23}$ Informal logicians, as evidenced by textbooks and pedagogical discussions in the field, generally reflect a common focus on first level undergraduate courses in argument analysis or critical thinking that purport to offer students general and subject neutral strategies that include a common core of epistemological concepts, logical skills and student traits taken as central to the enterprise.

The textbooks in the field, in addition, point to a domain of application for the abilities and dispositions developed through their use. The majority of available texts draw material from the popular press, from media and from political discourse. Less frequently, material is drawn from student level philosophy texts, but these text fragments are rarely, if ever, systematically explored. Rather, materials offered as examples or in exercises, are abstracted from their context and presented within a format that addresses the skill or concept they are taken to exemplify. Short fragments, whether newspaper editorials, or short passages drawn from some nontechnical discipline such as history, do little to represent argument as it occurs in the domain from which it has been abstracted, Rather, informal logic and critical thinking texts present for the student short segments of reasoned discourse in order to afford the opportunity for the presentation and application of a particular informal logic concept. This impression, garnered from most available texts, is reinforced by the statements of advocates of critical thinking. The claim, characterisitic of most members of the field, is that critical thinking is generally applicable and subject neutral. This has been most apparent in the responses of members of the informal logic community to John McPeck's challenge in Critical Thinking and Education (McPeck, 1981). McPeck faulted the movement on the grounds that general and subject neutral critical thinking was vacuous. Critical thinking, he argued, requires a subject domain for its appropriate application, and varies in accordance with the methodological principles that characterize inquiry in the various areas of knowledge. Rather than rejecting subject neutrality as an essential characteristic of critical thinking, informal logic theorists offered arguments for the relevance of subject neutral skills to the objectives for which critical thinking instruction was envisioned (Weddle, 1984; Paul, 1985; Ennis, 1989).

Richard Paul, for example, argued that discipline neutrality is crucial since the most important problems for which critical thinking is required are not resolvable within the academic disciplines. Paul maintained that the most crucial domain of application for critical thought is problems that are "multi-logical" and "dialogical," problems that are inimical to discipline specific perspectives and training, involving issues that require a variety of perspectives for their analysis and assessment, as contrasted to issues that can be adequately dealt with within a particular framework (Paul, 1982). This became a common theme in discussions of McPeck and reflects a position that has been generally accepted by the field: critical thinking includes a generalizable set of skills applicable to the complex and frequently illstructured problems of daily life, closely identified with aspects of informal logic.

24 The phrase "epistemology of the disciplines" has been used by McPeck (1981). My use of the concept goes back to my work on the "Map of Knowledge," See Weinstein (1985).

25 Weinstein (1988b) offers the briefest preliminary sketch of what an "ecological perspective" includes. It includes a distinction between two senses of "normative" relevant to critical thinking across the disciplines. First, "normative" in the sense of disciplines that traditionally take a normative stance that is meta-disciplinary, including disciplines as diverse as formal and informal logic, argumentation theory, various theories of discourse analysis, cognitive and educational psychology, curriculum theory and theories of educational institutions, as well as theories that support social, cultural and political critique, and sociology of knowledge of many sorts. Second, "normative" in the sense of normatively constituted and constituting practices within a discipline itself: that is, the disciplinary "standards in use that govern knowledge production, transmission and evaluation" (ibid, , p, 8.).

26 For the relationship between philosophy and critical thinking, and a portrayal of philosophy as a discipline that reflects a commitment to particular styles of analysis and argumentation, see Weinstein (1988c; 1988d).

27 Siegel (1987, chapter 1). 
28 Siegel $(1980 ; 1987 ; 1988$, chapter 2$)$ seems to sustain, without developing the position in any detail, the relevance, if not superiority of philosophical epistemology in some general philosophical sense. We have looked at this in some detail in $n$. 8. An anonymous referee sees my argument as "unconvincing," claiming that it falls most naturally to philosophy to "chart the course of such questions as 'Do different subject matters admit (or require) significantly different epistemological treatment?" The referee does, however, seem to agree with my position in that he or she claims that the answer to the question just quoted, "has been YES since Aristotle's time. "How "convincing" my argument is, of course, remains to be seen. Nevertheless, the reviewer seems to confuse the historic role of philosophy as an essential forum within which fundamental methodological and epistemological questions are raised, and the saliency of philosophical approaches to furnishing answers for such questions. As I have tried to show in the papers cited in n. 26, philosophers, although focusing on foundational questions of the most general kind, structure and respond to such questions in particular ways, and in a fashion distinguishable from how such questions are construed in other similarly foundational disciplines. The unique relevance of philosophical perspectives is currently disputed by scholars who reject the a priorism of most recent and traditional philosophy. The question cannot be resolved by calling attention to the historic role of philosophy in regards fundamental issues without begging the very point at issue.

The referee also suggests that I offer examples of "applied epistemologies" incompatible (incommensurable?) with each other and with "pure" epistemology." A recent example of applied epistemology is Stephen Jay Gould's Wonderfil Life, where the essential role of substantive empirical and methodological issues, specific to paleontology, are shown to qualify the most fundamental aspects of evolutionary theory, aspects that had, heretofore, been decided on a prioristic grounds (Gould, 1989). Is Gould's work incompatible or incommensurable with purely philosophical epistemology? A preliminary question must be answered first. Could a philosopher, utilizing concepts drawn from traditional or contemporary epistemolgy have seen what Gould describes? Similar points could be made in respect of the profound effect of quantum indeterminancy on philosophical discussions of causation, the consequences of recent literary theory on the availability of objective analyses of texts (Eagleton, 1983) and the movement within the history of ideas that sees social and historical contingencies as essential for epistemological understanding (See, for example, Bernstein, 1983, for a synthesis of recent socially and historically sensitive views of central relevance to epistemology).

29

Robert Swartz and David Perkins (1989), in an extremely useful book that speaks to teachers at all educational levels, offer a "Map of Causal Explanation." It consists of four question that are intended to direct inquiry: " 1 . What are the possible causes of the event in question? 2. What could you find that would count for and against the likelihood of these possibilities? 3 . What evidence do you already have, or have you gathered that is relevant to determining the cause? 4 . What possibility is rendered most likely, based on the evidence? (p. 77)." What is clear to me is that it is, in general, impossible to answer these questions without substantive knowledge from domains within which a given causal explanation is offered. By substantive knowledge I don't only mean "facts," but principles that determine what sort of weight is to be assigned to the considerations that support a given causal claim and the principles that support the strength and reliability of the assignment of weights themselves. Kahane (1979) offers a similarly schematic account that raises similar issues. The fallacy of Questionable Cause is assigned, he says, "if we label a given thing as the cause of something else on the basis of insufficient or inappropriate evidence." Again one feels the need to touch methodological ground. By what criteria are kinds of evidence deemed insufficient or inappropriate? Is there a general account of such criteria? And if not, where but into the disciplines are we to go for our answer? And so it seems that it is only within the various domains that the relevant alternatives can be identified, their adequacy relevantly assessed and judgments of insufficiency and inappropriateness made.

It is reasonable to complain that the opentextured examples of analyses of causation by informal logicians and critical thinking specialists that I choose unfairly represents the analyses available in the current literature. Kahane, who I cite above, spends only two pages on the causal fallacy, whereas Johnson and Blair (1983) spend ten, and Govier (1985) spends perhaps as many as four of her chapters on factors relevant to causal claims. These 
authors offer rich and complex argument types, patterns and distinctions for their students to consider. But we may ask: What characteristic limits do these analyses and examples include? Are they, for example, relevant across the disciplines students learn within the courses they take in their undergraduate education?

Johnson and Blair, as is their practice, draw examples from complex causal issues in daily life. Two questions arise: first, can the structures they identify illuminate issues within the disciplines and second, can issues of the type they present be adequately assessed without disciplinary knowledge, and with an appropriate level of sophistication. (See Weinstein, 1990c for a hopefully provocative analysis of a lighthearted example of Perry Weddle's.)

Govier's text is strong on causal arguments. The chapter in which she deals specifically with causal issues connects them to "social life" and so the examples include social science issues, when they do not reflect "daily life." This, to me, is a step in the right direction; her terminology reflects central issues in the domain she explores, e.g. correlation, and the questions her exercises and examples raise, reflect social knowledge at a degree of sophistication that is rightly required of college undergraduates. Her choice of topic is, however, telling. First, she chooses one topic among many relevant to causal analysis; second, she chooses a topic that is rich in its relevance to many ordinary concerns and is thereby likely to activate students' prior knowledge and prompt additional research. This raises two questions: First, how much knowledge of facts, of appropriate theories and of method, above and beyond the informal logic structures she provides, is smuggled into a classroom discussion or homework assignment adequate to the phenomena presented for analysis and assessment? That is, how much of what she teaches is functioning essentially, and how much of the success of her enterprise is based on what the students bring to the forum she provides? Second, would similar exercises from the wide range of areas students study in college be as available to their untutored analysis? This raises the issue of division of labor, an issue that Govier is particularly sensitive to (Govier, 1987, chapter 11). To what extent do critical thinking outcomes require that informal logic be a mere beginning to a process that must continue throughout many, if not all, of the courses students take? And if such an outcome is required, what is the role that critical thinking advocates and informal logicians must play in institutional reform at the undergraduate level in particular? (See sections 5 and 6, below, and n. 37.)

\section{Lipman (1988).}

31 The idea of a language game has exercised philosophers since it was introduced in the Philosophical Investigations (Wittgenstein, 1953). Seeing language as essentially tied to use, and language use as embedded in practice, ties reasoning, and therefore critical thinking. to the justificatory context from which analysis and assessment take their substance. Such a notion rejects a priorism and rather looks to a foundation in socially constituted and historically validated practice. This is obviously tied to inquiry in the sense of Dewey (1933) and has a deep affinity with anti-formalist tendencies in logic and philosophy of science. The connection of language use with the deep and perplexing notion of form of life reinforces this interpretation. Besides for the oft-cited occurence of "form of life" in the Investigations (Wittgenstein, 1958, paragraphs, 19, 23 and 248 . and pp. 174, 226), see 142 for a telling instance, also $144-6 ; 198-9$. I find related comments in Remarks on the Foundations of Mathematics (Wittgenstein, 1956) particularly illuminating, especially Part I, paragraphs 142-155. The section on translatability and proof on Part II, paragraphs 65-76 are also relevant, emphasizing the constructive nature of proofs and difficulties with translatability of proofs to languages that reflect different practices. Also relevant are sections of On Certainty, (Wittgenstein, 1969) particularly the paragraphs surrounding the suggestive use of "acting" in paragraph 204 and similarly seminal analyses in paragraphs 348 . 475,519 and 609 .

32 This raises a crucial question that has been rarely, if ever, discussed in the critical thinking literature: How do argument analyses typical of informal logic or critical thinking look from the perspectives of the various disciplines through which we want to inform students, or remediate their cognitive deficits, or clarify issues, or support cogent reasoning? How does the practice of informal logic look to fields that have their own standard for the presentation and the elaboration of argumentation and especially for assessing students' ability to understand and manipulate argumentation appropriate to the subject area the student is called on to master?

33 Siegel (1988) pp. 54ff. 
${ }^{34}$ Perhaps I am too harsh, relying on my experience with early texts in the field, where I found the combination of a blatant political agenda with superficial analyses both unsupportable and inadequate to the task of helping students develop even a modest competence in dealing with complex actual issues (Weinstein. 1982). Textbooks have certainly improved since the earliest (but still best selling) offerings in the field. And, perhaps, simple distinctions, even caricatures, are helpful as memorable "first approximations." Perry Weddle never fails to give me pause by reminding me that even as rough and ready a distinction as that between correlation and cause can serve to make students pause in their consideration of indefinitely many claims about the world around them. This is certainly valuable; critical thinking courses may serve the students well if they do no more than develop a budget of reminders relevant to their daily and academic lives.

But my concern persists. My problem is similar to that which prompted Richard Paul's rejection of "weak sense" critical thinking (Paul, 1982), although I am less concerned with the facile rejection of positions that students find unappealing, than with the sophomoric rejection of positions worthy of careful consideration, aided and abetted by the standard treatment of fallacies through decontextualized examples in informal logic texts. Distinctions such as that between correlation and cause are certainly essential, but they play no role unless the student has a sense of what, for example, counts towards supporting a causal claim as opposed to a mere correlation. It is my contention that this cannot be decided in general, and in a manner indifferent to the way that causal claims are constituted in the particular domains within which causal arguments occur. Rather they require substantive generalizations from various relevant fields, complete with the methodological and theoretical apparatus necessary for causal argument in the particular fields involved. (See note 29.)

The anonymous referee questions the implications of my view for the "instructional program" generated by recent concern with critical thinking, reminding me that "CT-ers have people for 13 weeks in their freshman or sophmore years." This echoes Trudy Govier's call for a division of academic labor, limiting informal logic and critical thinking to "those aspects of arguments which are universal, universal within a sub-class, or at least relatively common" (Govier, 1987, p. 231), Obviously, no one argues that critical thinking encompasses all of the knowledge required for evaluating claims across the college curriculum, although definitions such as Ennis's, and programs such as Siegel's, invite just the sort of broad objectives that Govier foreswears. The question for advocates of educational reform through critical thinking is to identify the optimal strategy for utilizing the thirteen weeks at their disposal, and more to the point, to develop strategies for enlisting the support of instructors of other disciplines in the task at hand. It is not enough to fall back on the fact that we can do very litthe, when we claim to do a great deal. It is even worse to claim to do a great deal that is doable with a concerted effort involving many friends and co-workers, while limiting oneself to going it alone on the grounds of academic turf or methodological purity.

${ }^{35}$ Siegel (1988), pp. 28ff. For his advocacy of pluralism, see Siegel (1987), especially chapter 8 .

36 I share the concern expressed by Paul, (1985) that undergraduate students not be taught to be narrow specialists, or think that real problems are completely resolvable by "specialized knowledge," or feel that they have to "suspend judgment and/or defer to experts." "Where we may differ is in regards to the desirability and the educational devices required if students are to become, what Paul disparagingly calls "specialists on specialists," that is a person who can access and meaningfully employ specialists" knowledge. I also may differ with Paul on the role that I assign to specialist's knowledge, for I see special knowledge within the disciplines as offering the best available accounts of those aspects of the world that fall within their domain of expertise. (This, of course, includes the specialized knowledge of philosophers, informal logicians and critical thinking theorists.) And so I see a major task of critical thinking to be helping students understand that special knowledge is required, what aspects of complex problems are amenable to which special knowledge, and how best to assess the claims of specialists, both in terms of appropriate criteria in relevant fields, and in terms of the context of application. If we add to this that students begin the process of understanding the appropriate criteria for choosing between various sorts of specialized claims to both facticity and relevance, and that students understand and apply the criteriological considerations that support such claims, by drawing from particular fields, including broadly relevant fields 
such as philosophy and informal logic, we have a model for critical thinking adequate to the education of undergraduates, and one that requires a broadly based and energetic program of institutional and educational reform.

37 The faculty development project of the Institute for Critical Thinking at Montclair State College is described in Weinstein and OxmanMichelli (1989).

38 Pedagogical issues have been aptly summarized in Paul (1988); Siegel (1988) addresses issues of relevance in chapters 6 and 7; Govier
(1987) has much to say in chapter 12. For me the locus classicus of the complaint is Lipman, et al. (1980).

39 Problems involving students' expectations and their concomitant resistance to critical thinking are all too familiar to converts to critical thinking pedagogy who watch their student evaluations fall as students respond to the unilateral breaking of the tacit contract underlying undergraduate studies: Professors profess, students regurgitate. See Oxman (1989) and Perry (1968) for relevant analyses.

\section{Bibliography}

Bernstein, R.J. (1985) Beyond Objectivism and Relativism. London: Basil Blackwell.

Cohen, L.J. (1981) "Can Human Irrationality Be Experimentally Demonstrated?" Behavioral and Brain Sciences, 4, 317-370.

Dewey, J. (1933) How We Think. Lexington, MA: D.C. Heath.

Eagleton, T. (1983) Literary Theory. Minneapolis: University of Minnesota Press.

Eberle, R.D., Kaplan, D. and Montague, R. (1961) "Hempel and Oppenheim on Explanation." Philosophy of Science, 28, 418-28.

Ennis, R.H. (1962) " A Concept of Critical Thinking." Harvard Educational Review, 32:1, 81-111.

(1987) " A Taxonomy of Critical Thinking Skills and Dispositions." J. Baron and R. Sternberg (eds.) Teaching for Thinking. New York: Freeman, 1987, 9-26.

(1989) "Critical Thinking and Subject Specificity: Clarification and Needed Research." Educational Researcher, 18, 4-10.

Fisher, A. (1988) "Introduction." A. Fisher (ed,), Critical Thinking: Proceedings of the First British Conference on Informal Logic and Critical Thinking. East Anglia: University of East Anglia, 1988, 1-12.

Freeman J.B, (1988) Thinking Logically. Englewood Cliffs, NJ: Prentice Hall.

Gould, S.J. (1989) Wonderful Life. New York: Norton.

Govier, T. (1985) A Practical Study of Argument. Belmont, CA: Wadsworth.
(1987) Problems in Argument Analysis and Evaluation. Dordrecht, Holland: Foris.

Grootendorst, R. (1989) "What a Pragmadialectical Approach to Fallacies Can and Cannot Do." Paper read at the Third International Symposium on Informal Logic, at the University of Windsor, June, 1989.

Harman, G. (1977) The Nature of Morality. New York: Oxford University Press.

Hempel, C.G. (1965) Aspects of Scientific Explanation. New York: Free Press.

Hintakka, J. (1989) "The Role of Logic in Argumentation." The Monist, 72:1, 3-24.

Hirst, P.H. (1965) "Liberal Education and the Nature of Knowledge." R.D. Archambault (ed.) Philosophical Analysis in Education. London: Routledge, 1965, 113-138.

Johnson, R.H. (1981) "Toulmin's Bold Experiment." Informal Logic Newsletter, 3:2, 16-27; $3: 3,13-19$.

Johnson, R.H. and Blair, J.A. (1983) Logical SelfDefense. Toronto: McGraw-Hill Ryerson.

Kahane, H. (1980) Logic and Contemporary Rhetoric, Belmont, CA: Wadsworth.

(1984) "John Nolt's Inductive Reasoning Test." Informal Logic, 6:3, 30.

Kruiger, T. (1989) "The Evaluation of Subordinative Argumentation." Paper read at the Third International Symposium on Informal Logic, at the University of Windsor, June, 1989.

Lipman, M. (1988) "Critical Thinking: What Can It Be?" Resource Publication, 1:1. Upper Montclair, NJ: Institute for Critical Thinking. 
Lipman, M., Sharp, A.M. \& Oscanyan, F. (1980) Philosophy in the Classroom. Philadelphia: Temple University Press.

Manicus, P.T. (1966) "On Toulmin's Contributions to Logic and Argument." Journal of the American Forensic Association, 3, 83-94.

Margolis, H. (1987) Patterns, Thinking, and Cognition. Chicago: University of Chicago Press.

McPeck, J. (1981) Critical Thinking and Education. New York: St. Martin's Press.

Oxman, W. (1989) "Academic Tasks and the Development of Critical Thinking Dispositions." Forthcoming. Upper Montclair, NJ: Institute for Critical Thinking.

Paul. R. (1982) "Teaching Critical Thinking in the "Strong Sense: A Focus on Self-Deception, World Views and a Dialectical Mode of Analysis," in Informal Logic Newsletter, 4:2, $2-7$.

Logic, 7:1, 35-43.

(1988) "Two Conflicting Theories of Knowledge, Learning and Literacy: The Didactic and the Critical." Resource Publication, 1:2. Upper Montclair, NJ: Institute for Critical Thinking.

Perry, W.G. (1968) Intellectual and Ethical Development in the College Years. New York: Holt, Rinehart and Winston.

Phillips, D.C. (1971) "The Distinguishing Features of Forms of Knowledge." Educational Philosophy and Theory, 3, 27-35.

Ryle, G. (1949) The Concept of Mind. New York: Barnes and Noble.

Siegel, H. (1980) "Justification, Discovery and the Naturalizing of Epistemology." Philosophy of Science, 47:2, 297-232. Reidel.

(1987) Relativism Refuted. Dordrecht:

(1988) Educating Reason: Rationality, Critical Thinking and Education. New York: Routledge.

Suppes, P. (1966) "Probabilistic Inference and the Concept of Total Evidence." Hintikka, J. and Suppes, P. (eds.) Aspects of Inductive Logic. Amsterdam: North Holland, 1966, 49-65.

Swartz, R.J. and Perkins, R.H. (1989) Teaching Thinking: Issues and Approaches. Pacific Grove, CA: Midwest.
Thomas, S. (1984) "Degress of Validity and Ratios of Conceivable Worlds, "Informal Logic, 6:3, 31-34.

Toulmin, S. (1953) The Philosophy of Science. London: Hutchinson Library.

(1969) The Uses of Argument. 2nd edition, Cambridge: Cambridge University Press.

\& Goodfield, J. (1961) The Fabric of the Heavens. New York: Harper and Row.

\& Goodfield, J. (1962) The Architecture of Matter. New York: Harper and Row.

\& Goodfield, J. (1965) The Discovery of Time. Chicago: University of Chicago Press.

, Rieke, R. \& Janik, A. (1979) An Introduction to Reasoning. New York: Macmillan.

Weddle, P. (1984) "McPeck"s Critical Thinking and Education," Informal Logic, 6:2, 23-25.

Weinstein, M. (1982) "Musclebuilding for 'Strength' in Critical Thinking." Informal Logic Newsletter 5:1, 13-17.

(1985) "Philosophy and the General Curriculum: the Map of Knowledge." Metaphilosophy, 16:2, 239-249.

(1988a) "Reason and Critical Thinking." Informal Logic, 10:1, 1-20.

(1988b) "Critical Thinking in the Disciplines: An Ecological Approach." Inquiry: Critical Thinking Across the Disciplines, 1:3-8.

(1988c) "Philosophy and Critical Thinking: A Personal Perspective." Inquiry: Critical Thinking Across the Disciplines, 1:4, 3-6.

(1988d) "Philosophy, Criteria and Scholarship." Inquiry: Critical Thinking Across the Disciplines, 2:1, 3-12.

(1989) "Critical Thinking and Basic Skills Reading." Inquiry: Critical Thinking Across the Disciplines, 3:4, 7-8.

(1990a) Critical Thinking and the Psycho-logic of Race Prejudice." Resource Publication, 3:1. Upper Montclair, NJ: Institute for Critical Thinking.

(1990b) "Entailment in Argumen tation." Forthcoming. Proceedings of the Second International Conference on Argumentation. 
Weinstein, M. (1990c) "Informal Logic and Applied Epistemology." Resource Publication, 3:4. Upper Montclair, NJ: Institute for Critical Thinking.

(1990d) "Review of Educating Reason: Rationality, Critical Thinking and Education." Educational Studies, 20:4, 413-421. (1990e) "Towards an Account of Argumentation in Science." Argumentaion, 4, 269-298.

\& Oxman-Michelli, W. (1989) "The Faculty Development Program of the Institute for Critical Thinking,' Inquiry: Critical Thinking Across the Disciplines, 4:3, 9-13.
Wittgenstein, L. (1953) Philosophical Investigations. New York: Macmillan.

(1956) Remarks on the Foundations of Mathematics. Cambridge, MA: MIT Press. and Row.

(1969) On Certainty. New York: Harper

MARK WEINSTEIN

INSTITUTE FOR CRITICAL THINKING

MONTCLAIR STATE COLLEGE

UPPER MONTCLAIR, N.J. 07043 